\title{
Peningkatan Kompetensi Guru Memanfaatkan Media Pembelajaran Berbasis IT Melalui IHT di Sekolah Dasar
}

\author{
Jasmiati \\ Sekolah Dasar Negeri 05 Gunuang Malintang, Lima Puluh Kota \\ E-mail: jasmiatino@gmail.com
}

\begin{abstract}
School Action Research is intended to improve the ability of teachers to use Information Technology-Based Learning Media. The study was conducted at Sekolah Dasar Negeri 05 Gunuang Malintang with 12 subjects. The data collected through observation, interviews, and tests indicated that the ability to utilize ITbased learning media can be improved through In House Training (IHT). The steps of IHT activities are as follows: (1) Share the initial test with the teacher, (2) The teacher works on the initial test to determine the ability to use and utilize IT as a learning medium. (5) Provide material perceptions about the use of IT-based learning media. (6. Provide services and guidance to teachers about the use of IT. (7) Providing opportunities for teachers to create and innovate in utilizing IT as a learning media. (8) Provide services and guidance to teachers during IHT. (9) Give the final test.
\end{abstract}

Keywords: Competency, Instructional Media, Information Technology, House Training

cC (\$) Licensees may copy, distribute, display and perform the work and make derivative works and remixes based on it only if they give the author or licensor the credits (attribution) in the manner specified by these. Licensees may copy, distribute, display, and perform the work and make derivative works and remixes based on it only for non-commercial purposes.

\section{PENDAHULUAN}

Kepala sekolah adalah guru yang diserahi tugas tambahan untuk memimpin dan mengelola sekolah dalam upaya meningkatkan mutu pendidikan (Syamsul, 2017). Peraturan Menteri Pendidikan Nasional nomor 13 tahun 2007 tentang Standar Kepala Sekolah/Madrasah menyatakan 5 (lima) dimensi kompetensi yang harus dimiliki Kepala Sekolah/Madrasah, yaitu kompetensi kepribadian, manajerial, kewirausahaan, supervisi, dan kompetensi sosial, teknik pelaksanaan.

Kompetensi kepala sekolah yang berhubungan dengan peningkatan keprofesionalan guru adalah kompetensi profesional. Kompetensi profesional guru menurut Permendiknas Nomor 35 Tahun 2010 guru dituntut untuk mampu menguasai materi, menyertakan informasi yang tepat dan mutakhir dalam RPP, melakukan evaluasi diri, mengaplikasikan PKB dalam menyusun administrasi pembelajaran, melakukan penelitian, dan memanfaatkan Information Technology (IT) dalam pembelajaran (Fitriani, AR, \& Usman, 2017).

Guru sebagai fasilitator mempunyai banyak peran, harus mampu memilih dan mengolah metode, strategi, dan motif mengajar yang dapat meningkatkan minat belajar para peserta didik (Hadiyanto, 2004). Salah satu media tersebut adalah IT. Jadi, apabila guru mampu IT serta dapat memanfaatkan IT dalam proses pembelajaran salah satu cerminan guru 
yang profesional. Guru yang profesional akan berdampak pada mutu pendidikan.

Sehubungan dengan peningkatan profesional guru dapat dilakukan dengan melaksanakan pelatihan-pelatihan. Pelatihan dapat diberikan di KKG atau di sekolah. Misalnya pelatihan menggunakan IT bagi guru yang belum mampu menggunakan IT (Rusdin, 2017).

Kemampuan guru SDN 05 Gunuang Malintang memanfaatkan media pembelajaran berbasis IT sangat kurang. Hal ini terbukti ketika kepala sekolah melaksanakan supervisi akademik dari 6 orang guru kelas hanya 1 orang yang menggunakan IT dalam proses pembelajaran. Guru mata pelajaran, guru agama, olah raga, dan BAM belum menggunakan IT dalam proses pembelajaran. Selanjutnya ketika dilaksanakan tes awal menggunakan IT yang diikuti 12 orang guru hanya memperoleh rata-rata klasikal 62,81.

Untuk mengatasi hal tersebut, Kepala Sekolah Dasar Negeri 05 Gunuang Malintang perlu melatih guru menggunakan IT serta membimbing guru memanfaatkan IT dalam proses pembelajaran. Salah satu pelatihan yang dapat diberikan pada guru yaitu melalui kegiatan In House Training (IHT).

Berdasarkan penjelasan di atas, kepala sekolah Sekolah Dasar Negeri 05 Gunuang Malintang perlu melakukan Penelitian Tindakan Sekolah. Rumusan masalah pada penelitian ini adalah Bagaimana proses peningkatan kemampuan guru memanfaatkan media pembelajaran berbasis IT melalui IHT di SDN 05 Gunuang Malintang?

\section{METODE}

Sesuai dengan masalah dan tujuan yang hendak dicapai, jenis penelitian yang digunakan adalah Penelitian Tindakan Sekolah (PTS) atau Clasroom Action Research. PTS yang dilakukan berdasarkan teori Penelitian Tindakan Kelas (PTK). Subyek penelitian ini adalah guru SDN 05 Gunuang Malintang, yang terdaftar pada tahun ajaran 2016/2017. Guru berjumlah 12 orang, perempuan 11 orang, lakilaki 1 orang SDN 05 Gunuang Malintang berada di Kecamatan Pangkalan Koto Baru, Kabupaten Lima Puluh Kota, Sumatera Barat. Lokasinya di daerah Gunuang Malintang, kira- kira $15 \mathrm{~km}$ dari jalan raya Payakumbuh-Pakan Baru. Jumlah siswa 141 orang dengan guru 13 orang. Penelitian dilaksanakan pada semester II tahun ajaran 2016/2017 (Januari, Februari, Maret, April).

Penelitian ini menggunakan model Penelitian Tindakan Kelas (PTK). Desain penelitian yang digunakan adalah model Arikunto (2015) yang terdiri dari empat komponen, yaitu, (1) perencanaan (planning) pelaksanaan (action), (3) pengamatan (observing), (4) refleksi (reflekting). Penelitian ini berlangsung 2 siklus. Setiap siklus terdiri dari tiga kali pertemuan. Siklus I yang terdiri dari 3 kali pertemuan. Langkah-langkah kegiatan IHT menurut Khaerani (2016) adalah sebagai berikut : (1) Membagikan tes awal kepada guru; (2) Guru mengerjakan tes awal untuk mengetahui kemampuan menggunakan serta memanfaatkan IT sebagai media pembelajaran; (3) Memberikan materi apersepsi tentang pemanfaatan media pembelajaran berbasis IT; (4).Memberikan layanan dan bimbingan kepada guru tentang penggunan IT; (5) Memberikan kesempatan kepada guru untuk berkreatif dan berinovatif dalam memanfaatkan IT sebagai media pembelajaran; (6) Memberikan layanan dan bimbingan kepada guru selama IHT berlangsung dan (9) Memberikan tes akhir.

Langkah-langkah pembelajaran pada siklus I, secara garis besar sama dengan langkah-langkah pembelajaran pada siklus II. Bedanya pada siklus II tujuan kegiatan yang sudah dipahami guru tidak dikaji lagi. Sehubungan dengan pendapat di atas, sumber data dalam penelitian ini dibedakan menjadi dua yaitu dari kepala sekolah sebagai pelaksana kegiatan IHT dan dari guru sebagai peserta kegiatan IHT. Data penelitian berupa data kualitatif dan kuantitatif. Data kualitatif berupa tindakan kepala sekolah sebagai pelaksana kegiatan IHT dan tindakan guru sebagai peserta kegiatan IHT dipaparkan atau dideskriptifkan. Data kuantitatif berupa hasil tes guru menggunakan IT. Instrumen penelitian lembaran observasi dan format penilaian peer teaching. Jumlah skor tes berkisar antara 0100 , yang terkelompok pada setiap indikator. 


\section{HASIL PENELITIAN DAN PEMBAHASAN}

\section{Pra Siklus}

Berdasarkan permasalahan yang ditemui pada guru di SDN 05 Gunuang Malintang ketika orientasi dan observasi dalam menggunakan IT dan pemanfatan media pembelajaran berbasis IT, ternyata dari jumlah guru 12 orang terdapat 8 orang $(66,66 \%)$, yang sudah mampu IT sedangkan 4 orang $(33,33)$ kurang mampu IT. Terkait dengan hal tersebut jumlah guru yang mampu IT 8 orang, hanya 1 orang, $(12,5 \%)$ yang memanfaatkan IT sebagai media pembelajaran. Oleh sebab itu, dilaksanakan tindakan dengan suatu kegiatan In House Training (IHT).

\section{Siklus I}

Berdasarkan hasil observasi penyelenggara IHT, catatan lapangan, dan wawancara terhadap guru disimpulkan bahwa penyelenggara IHT telah melaksanakan kegiatan sesuai dengan panduan. Merujuk hasil tes peserta $I H T$, hasil instrumen monev, catatan lapangan peserta telah mengerjakan tugas dengan tanggung jawab, dapat membantu teman sejawat yang mengalami kesulitan dalam memanfaatkan media pembelajaran berbasis IT. Ketika veer teaching guru sudah mampu memanfaatkan IT sebagai media pembelajaran. Namun aspek kejelasan gambar dan tulisan masih kurang.Pengaruh warna sehingga tulisan kurang jelas. Dengan demikian dapat disimpulkan bahwa guru SDN 05 Gunuang Malintang, sudah mengalami peningkatan dalam memanfaatkan media pembelajaran berbasis IT, namun perlu ditingkatkan dari aspek kejelasan gambar. Oleh sebab itu, kegiatan IHT perlu dilanjutkan ke siklus II.

\section{Siklus II}

Berdasarkan hasil observasi atau monev penyelenggara IHT, catatan lapangan, dan wawancara terhadap guru disimpulkan bahwa penyelenggara IHT telah melaksanakan kegiatan sesuai dengan panduan. Merujuk hasil tes, hasil peer teaching peserta IHT, hasil instrumen monev, catatan lapangan, peserta dalam mengerjakan tugas sudah bertanggung jawab. Media yang dibuat guru juga sudah sesuai materi. Tulisan atau gambar yang ditayangkan melalui $L C D$ juga sudah jelas. Kreativitas guru juga sudah tampak. Ketika dilaksanakan supervisi akademik setelah selesai siklus II, dari 6 orang guru kelas sudah 4 orang yang menggunakan IT sebagai media pembelajaran. Dengan demikian dapat disimpulkan bahwa guru SDN 05 Gunuang Malintang, sudah mengalami peningkatan dalam memanfaatkan media pembelajaran berbasis IT. Oleh sebab itu, kegiatan IHT tidak perlu dilanjutkan ke siklus berikutnya.

Untuk lebih jelasnya mari kita lihat tabel perbandingan nilai rata-rata hasil tes menggunakan IT, hasil peer teaching, dan hasil monev peserta kegiatan Pra Siklus, Siklus I dan Siklus II di bawah ini.

Tabel 1. Rekap Nilai Hasil Tes Menggunakan IT pada Pra Siklus, Siklus I dan Siklus II

\begin{tabular}{llccc}
\hline No & Nama Guru & $\begin{array}{l}\text { Pra } \\
\text { Siklus }\end{array}$ & $\begin{array}{l}\text { Siklus } \\
\text { I }\end{array}$ & \multicolumn{2}{l}{ Siklus } \\
\hline 1 & Elismar,S.Pd.I & 56,66 & 66,66 & 83,33 \\
2 & Masratul & 56,66 & 63,00 & 83,33 \\
& Elfi,S.Pd & & & \\
3 & Elfia,S.Pd & 33,33 & 70,00 & 86,66 \\
4 & Haryatri & 86,66 & 90.00 & 93,33 \\
& Waewa,S.Pd & & & \\
5 & Resi Septia & 83,33 & 86,66 & 90,00 \\
& Putri, S.Pd & & & \\
6 & Devi & 86,66 & 90,00 & 93,33 \\
& Fitriyani,S.Pd & & & \\
7 & Desyi & 53,00 & 63,00 & 80,00 \\
& Yusnaini,S.Pd & & & \\
8 & Siti & 70,00 & 76,66 & 90,00 \\
& Marhumah,S.Pd & & & \\
9 & Rada & 67,00 & 76,66 & 90,00 \\
& Ramadhani & & & \\
10 & Dela & 56,70 & 70,00 & 76,66 \\
11 & Yati Fitri & 56,70 & 73,00 & 80,00 \\
12 & Eka & 53,00 & 63,00 & 80,00 \\
\hline & Jumlah & 753,8 & 888,32 & 1026,64 \\
\hline & Rata-rata & 62,81 & 74,02 & 85,55 \\
\hline
\end{tabular}

Tabel di atas menjelaskan bahwa kemampuan guru menggunakan IT meningkat. Hal ini terbukti, rata-rata nilai pra siklus 62,81 . Siklus I meningkat menjadi 74,02. Siklus II meningkat lagi menjadi 85,55. Nilai tertinggi pra siklus 86,66 , meningkat siklus II menjadi 90 diperoleh 2 orang guru. Siklus II meningkat rata-rata menjadi 85,55 . Nilai tertinggi 93,33 diperoleh 2 orang guru. 
Tabel 2. Hasil peer teaching Siklus I dan siklus II Memanfaatkan Media Pembelajaran Berbasis IT

\begin{tabular}{|c|c|c|c|c|c|c|c|}
\hline \multirow[t]{3}{*}{ No } & & \multicolumn{6}{|c|}{ Aspek yang Dinilai } \\
\hline & & \multicolumn{2}{|c|}{$\begin{array}{c}\text { Kesesuaian } \\
\text { Materi dgn Media }\end{array}$} & \multicolumn{2}{|c|}{$\begin{array}{c}\text { Kejelasan } \\
\text { gambar/tulisan }\end{array}$} & \multicolumn{2}{|c|}{$\begin{array}{c}\text { Keterampilan } \\
\text { menggunakan IT }\end{array}$} \\
\hline & & $\begin{array}{l}\text { Siklus } \\
\text { I }\end{array}$ & Siklus II & $\begin{array}{l}\text { Siklus } \\
\text { I }\end{array}$ & Siklus II & $\begin{array}{l}\text { Siklus } \\
\text { I }\end{array}$ & Siklus II \\
\hline 1 & Elismar,S.Pd.I & 3 & 4 & 2 & 3 & 2 & 3 \\
\hline 2 & $\begin{array}{l}\text { Masratul } \\
\text { Elfi,S.Pd }\end{array}$ & 3 & 4 & 2 & 3 & 2 & 3 \\
\hline 3 & Elfia & 3 & 4 & 2 & 3 & 2 & 3 \\
\hline 4 & $\begin{array}{l}\text { Haryatri } \\
\text { Waewa,S.Pd }\end{array}$ & 4 & 4 & 3 & 4 & 3 & 4 \\
\hline 5 & $\begin{array}{l}\text { Resi Septia } \\
\text { Putri, S.Pd }\end{array}$ & 3 & 4 & 3 & 4 & 3 & 4 \\
\hline 6 & $\begin{array}{l}\text { Devi } \\
\text { Fitriyani,S.Pd }\end{array}$ & 3 & 4 & 3 & 4 & 3 & 4 \\
\hline 7 & $\begin{array}{l}\text { Desyi } \\
\text { yusnaini,S.Pd }\end{array}$ & 3 & 3 & 2 & 3 & 3 & 3 \\
\hline 8 & $\begin{array}{l}\text { Siti } \\
\text { Marhumah,S.Pd }\end{array}$ & 3 & 4 & 2 & 4 & 2 & 3 \\
\hline 9 & Rada & 3 & 4 & 3 & 4 & 2 & 3 \\
\hline 10 & Dela & 3 & 3 & 3 & 3 & 2 & 3 \\
\hline 11 & Yati Fitri & 3 & 3 & 2 & 3 & 2 & 2 \\
\hline 12 & Eka & 3 & 3 & 3 & 3 & 2 & 3 \\
\hline & Jumlah & 37 & 44 & 31 & 41 & 28 & 38 \\
\hline & Rata-rata & 3.08 & 3.60 & 2.58 & 3,4 & 2.33 & 3,10 \\
\hline
\end{tabular}

Grafik di atas menjelaskan rata-rata

Data di atas menerangkan bahwa ratarata indikator kesesuaian media dengan materi siklus I 3,08 Siklus II naik menjadi 3,60. Indikator kejelasan tulisan/gambar ratarata siklus I 2,58, siklus II naik menjadi 3.40. Indikator kemampuan menggunakan IT ratarata siklus I, 2,33 siklus II naik menjadi 3,10

Dengan demikian, sudah ada peningkatan kemampuan guru yang memanfaatkan IT sebagai media media pembelajaran.

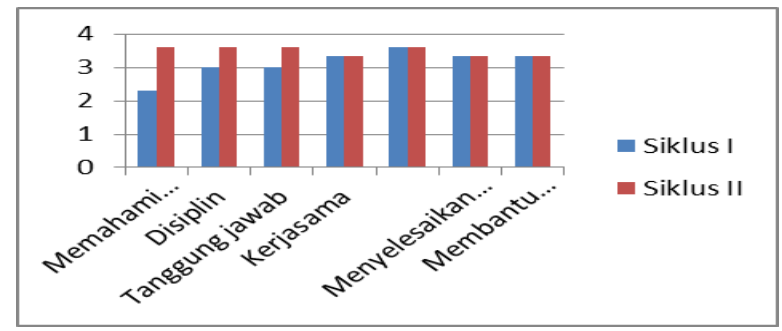

Grafik 1.

Perbandingan Hasil Monev Peserta IHT Siklus I dan Siklus II keaktifan peserta IHT siklus I dan siklus II meningkat. Siklus I rata-rata keaktivan peserta IHT 3,04 kategori baik. Siklus II ratarata keaktivan peserta $I H T$ naik menjadi 3,48 berkategori baik. Artinya peserta kegiatan IHT sudah mengikuti kegiatan dengan baik. Sehingga kemampuan guru memanfaatkan media pembelajaran berbasis IT juga meningkat.

Banyak faktor yang menyebabkan peningkatan kemampuan guru memanfaatkn media pembelajaran berbasis IT. Faktor ini dapat diketahui dari instrument monev, hasil catatan lapangan, dan wawancara dari guru (Ceha, Prasetyaningsih, Bachtiar, \& S, 2016). Faktor yang menyebabkan kemampuan guru meningkat memanfaatkan media pembelajaran berbasis IT adalah:

Pertama, Kegiatan IHT memberikan kesempatan kepada guru untuk berlatih memanfaatkan IT sebagai media pembelajaran.

Kedua, kegiatan IHT memberikan kesempatan kepada guru untuk berkreatif dan berinovatif dalam memanfaatkan media pembelajaran berbasis IT. 
Ketiga, kegiatan IHT memberi kesempatan kepada guru untuk belajar bersama teman sejawat. Keempat, kegiatan IHT memberikan kesempatan kepada guru untuk memahami program-program inovativ yang bisa meningkatkan kefektifan pelaksanaan pembelajaran. Kelima, kegiatan IHT memberi kesempatan kepada guru untuk bertanggung jawab dalam melaksanakan tugas pembelajaran.

\section{SIMPULAN DAN SARAN}

Dari hasil penelitian yang telah dipaparkan dapat diambil beberapa simpulan yaitu: (1) Kegiatan IHT dapat meningkatkan kemampuan guru memanfaatkan media pembelajaran berbasis IT. Hal ini dapat dilihat dari hasil tes guru pada kegiatan pra siklus, Siklus I, dan siklus II; (2) Berdasarkan hasil observasi, dalam mengikuti kegiatan IHT serta dalam pelaksanaan peer teaching guru sudah aktif dan kreatif. Berdasarkan kesimpulan di atas ada beberapa hal yang seharusnya dilakukan oleh kepala sekolah dalam meningkatkan kemampuan guru memanfaatkan media pembelajaran berbasis IT antara lain: (1) Melaksanakan pelatihan $I T$ di sekolah. Pelatihan IT dilaksanakan dengan melakukan kegiatan IHT; (2) Melengkapi sarana dan prasana yang menunjang guru agar mampu memanfaatkan IT sebagai media pembelajaran.

\section{DAFTAR PUSTAKA}

Arikunto, S. (2015). Penelitian Tindakan Kelas (Revisi). Jakarta: Bumi Aksara.

Ceha, R., Prasetyaningsih, E., Bachtiar, I., \& S, A. N. (2016). Peningkatan Kemampuan Guru dalam Pemanfaatan Teknologi Informasi pada Kegiatan Pembelajaran. Ethos (Jurnal Penelitian Dan Pengabdian Masyarakat), 4(1), 131-138.

Fitriani, C., AR, M., \& Usman, N. (2017). Kompetensi Profesional Guru dalam Pengelolaan Pembelajaran di MTs Muhammadiyah Banda Aceh. Jurnal Magister Administrasi Pendidikan
Pascasarjana Universitas Syiah Kuala, 5(2), 88-95.

Hadiyanto, H. (2004). Mencari Sosok Desentralisasi Manajemen Pendidikan di Indonesia. Jakarta: Rineka Cipta.

Khaerani, N. C. (2016). Peningkatan Kompetensi Guru dalam Menyusun RPP Melalui Kegiatan IHT (In House Training). Didaktikum: Jurnal Penelitian Tindakan Kelas, 17(1), 6470.

Rusdin. (2017). Pendidikan dan Pelatihan sebagai Sarana Peningkatan Kompetensi Guru di SMP Negeri 02 Linggang Bigung 1. Jurnal Administrative Reform, 5(4), 200-212.

Syamsul, H. (2017). Penerapan Kepemimpinan Kepala Sekolah dalam Meningkatkan Kinerja Guru pada Jenjang Sekolah Menengah Pertama (SMP). Jurnal Idaarah, I(2), 275-289. 